\title{
Interactive Effect of Food Compositions on the Migration Behavior of Printing Ink Solvent
}

\author{
Duek-Jun An \\ Department of Food Science, SunMoon University, Chungnam 336-840, Korea
}

\begin{abstract}
The partitioning behavior of the five printing ink solvents in nine lab-made cookies with various sugar and water content at $25^{\circ} \mathrm{C}$ was studied to find out the presence and effects of interaction between the two ingredients on partitioning behavior in cookies. Solvents were ethyl acetate, hexane, isopropanol, methyl ethyl ketone and hexane. It was observed that the partition coefficient (the solvent concentration in food compared to that in air, Kp) decreased as sugar increased in all case and increased as water content increased for all compounds except toluene. Statistical analysis by the F-test method was used to detemine the significance of sugar-water interactions, as well as other single factors on partitioning behavior of each solvent. Sugar content alone had no significant effects, but the crystallinity of sugar, as changed by water content, affected the partitioning behavior of the five solvents significantly. Parameter estimation for each significant factor by SAS program yielded a regression equation, which was used to predict the partitioning behavior in the finished cookie. Kp values from the regression equation could be detemined more precisely by applying a correction tem for the interaction between sugar and water to the $\mathrm{Kp}$ values of each ingredient after baking.
\end{abstract}

Key words: partitioning behavior, sugar and water interaction, F-test, regression equation, prediction of Kp value

\section{INTRODUCTION}

It is common practice to apply decorative coatings to flexible package materials to gain consumers' attention. The coating materials are generally dissolved or dispersed in solvents, and then applied to the packaging material with the subsequent removal of solvent by evaporation in the storage oven. However, a certain amount of residual solvents can remain (1), which can then migrate into the food by either direct contact or via the headspace inside the package. Migration of the residual solvents could generate off-flavor, deteriorate quality of the finished food, and even cause safety problems in the contained food.

The amount of solvent that enters the food depends on the partitioning of the solvents between the package materials and the contained food (2). Factors that influence this partitioning from the polymeric packaging materials into the single food compositions have been studied (3-7) and the results used to predict migration behavior $(8,9)$. However, factors that influence the partitioning to the total foods system are less understood. These factors include the chemical structure of the migration solvent and its interaction with the target food substrate. Some studies $(10,11)$ discuss the effects of structural change and interaction between some of the ingredients in the total food system on partitioning behavior is difficult to predict. Additional information about the effect of interactions between selected ingredients in the cookie is needed for understanding the migration behavior.

To satisfy this objective, factorial experiments were conducted to determine key interactions of several factors, and to derive a regression equation that could assign values to the included variables to predict $\mathrm{Kp}$ for different foods.

These factors included water and sugar, and the effect of sugar crystallinity on the partitioning behavior of the end product. Factorial experiment was conducted to determine the effects of sugar and water content of cookies at three different concentrations on the partitioning coefficient values of printing ink solvents. The other ingredients and their amounts were fixed at flour (37\%), chips (22.5\%), shortening (19\%), whole eff powder $(0.6 \%)$, whey $(0.3 \%)$. Five solvents (ethyl acetate, hexane, isopropanol, methyl ethyl ketone, toluene) which represent different specific functional groups were used and gas chromatography was used to measure ingredient sorption a closed system. 


\section{MATERIALS AND METHODS}

\section{Cookie ingredients and preparation of lab-made com- mercial cookie}

Chocolate-chips (Keebler Co., USA), Flour (General Mills Co., USA), white and brown sugar (Domino Sugar Corp., USA) and dried whole egg powder (High-grade egg products Inc, USA), whey powder from Sigma Co. and vegetable shortening from Proctor and Gamble Co. were used for lab-made cookies. Table 1 shows pre-

Table 1. Fat and water content of each cookie ingredient

(\%)

\begin{tabular}{llcc}
\hline Sample & & Fat content & Water content \\
\hline \multirow{2}{*}{ Shortening } & Raw & 93.2 & 0.0 \\
& Baked & 93.9 & 0.0 \\
\hline \multirow{2}{*}{ Whole egg } & Raw & 39.5 & 3.4 \\
& Baked & 41.7 & 1.1 \\
\hline \multirow{2}{*}{ Chocolate chips } & Raw & 25.6 & 1.8 \\
& Baked & 27.4 & 0.9 \\
\hline \multirow{2}{*}{ Flour } & Raw & 0.9 & 11.6 \\
& Baked & 1.1 & 5.6 \\
\multirow{2}{*}{ Whey powder } & Raw & 0.0 & 9.3 \\
& Baked & 0.0 & 4.1 \\
\hline \multirow{2}{*}{ White sugar } & Raw & 0.0 & 0.1 \\
& Baked & 0.0 & 0.1 \\
\multirow{2}{*}{ Brown sugar } & Raw & 0.0 & 0.3 \\
& Baked & 0.0 & 0.5 \\
\hline
\end{tabular}

viously determined fat and water content of raw and baked cookie ingredients. Shortening (19.1\% of total weight), brown sugar (2.4\%), white sugar (12.6\%), whole egg powder $(0.6 \%)$ and whey powder $(0.3 \%)$ were added to mix with some water (5.6\%). Finally flour (37.0\%) and chocolate chips (21.8\%) were added to make dough, the dough was stored overnight at room temperature, and then the cookies were baked at $260^{\circ} \mathrm{C}$ for $10 \mathrm{~min}$.

\section{Factorial expeniment design}

Factorial experiments using a combination of three different concentrations each of sugar and water were conducted to determine the effects of the contents on the partition coefficients of printing ink solvents. Table 2 shows possible combinations $(3 \times 3)$ of sugar and water contents based on total cookie weight.

The other cookie ingredients and their amounts remained fixed at flour (37\%), chips (22\%), shortening (19\%), whole egg powder (0.6\%), and whey (0.3\%). Table 3 shows formulation of cookie model systems for factorial experiments designed to study the effect of sugar and water concentration combinations on partitioning behavior of printing solvents. Lab-made cookies were prepared based on the cooking method of commercial recipes.

Presence of interaction or dependency between sugar and water at each level of the 9 combinations can be determined by drawing a diagram in which partition co-

Table 2. Combination of sugar and water contents for factorial experiment in 9 lab-made cookie

\begin{tabular}{|c|c|c|c|c|}
\hline & & \multicolumn{3}{|c|}{ Sugar } \\
\hline & & $10 \%$ & $15 \%$ & $20 \%$ \\
\hline \multirow{3}{*}{ Water } & $3 \%$ & $\begin{array}{l}\text { 10\% Sugar } \\
3 \% \text { Water }\end{array}$ & $\begin{array}{l}\text { 15\% Sugar } \\
3 \% \text { Water }\end{array}$ & $\begin{array}{l}20 \% \text { Sugar } \\
3 \% \text { Water }\end{array}$ \\
\hline & $6 \%$ & $\begin{array}{l}10 \% \text { Sugar } \\
6 \% \text { Water }\end{array}$ & $\begin{array}{l}\text { 15\% Sugar } \\
6 \% \text { Water }\end{array}$ & $\begin{array}{l}20 \% \text { Sugar } \\
6 \% \text { Water }\end{array}$ \\
\hline & $9 \%$ & $\begin{array}{l}10 \% \text { Sugar } \\
9 \% \text { Water }\end{array}$ & $\begin{array}{l}\text { 15\% Sugar } \\
9 \% \text { Water }\end{array}$ & $\begin{array}{l}20 \% \text { Sugar } \\
9 \% \text { Water }\end{array}$ \\
\hline
\end{tabular}

Total case 9

Table 3. Formation of cookie model systems for factorial experiment design to study the effect of sugar and water contents on partitioning behavior of printing solvents

\begin{tabular}{|c|c|c|c|c|c|c|c|c|c|}
\hline \multirow{2}{*}{$\begin{array}{l}\text { Ingredients }^{1)} \\
\text { Sugar }\end{array}$} & \multicolumn{9}{|c|}{ Weight compositions (\%) } \\
\hline & 10 & 15 & 20 & 10 & 15 & 20 & 10 & 15 & 20 \\
\hline White sugar & 8.4 & 12.6 & 16.8 & 8.4 & 12.6 & 16.8 & 8.4 & 12.6 & 16.8 \\
\hline Brown sugar & 1.6 & 2.4 & 3.2 & 1.6 & 2.4 & 3.2 & 1.6 & 2.4 & 3.2 \\
\hline Water & 2.7 & 2.7 & 2.7 & 5.1 & 5.1 & 5.1 & 9.4 & 9.4 & 9.4 \\
\hline Flour & 37.0 & 37.0 & 37.0 & 37.0 & 37.0 & 37.0 & 37.0 & 37.0 & 37.0 \\
\hline Chips & 21.8 & 21.8 & 21.8 & 21.8 & 21.8 & 21.8 & 21.8 & 21.8 & 21.8 \\
\hline Shortening & 19.1 & 19.1 & 19.1 & 19.1 & 19.1 & 19.1 & 19.1 & 19.1 & 19.1 \\
\hline Whole egg & 0.6 & 0.6 & 0.6 & 0.6 & 0.6 & 0.6 & 0.6 & 0.6 & 0.6 \\
\hline Whey powder & 0.3 & 0.3 & 0.3 & 0.3 & 0.3 & 0.3 & 0.3 & 0.3 & 0.3 \\
\hline
\end{tabular}

\footnotetext{
${ }^{1)}$ Weight compositions of each ingredient based on cookie weight (100 grams).
} 
efficient values were chosen as Y-axis and sugar or water factors were selected as $\mathrm{X}$-axis, alternatively. While parallel lines indicate that no interaction exists between sugar and water, intersecting lines imply that an interaction occurred between each factor.

\section{Measurement of fat and water content of 9 lab-made cookies}

Fat content of each lab-made cookie (5.0 g) was measured by the Soxhlet extraction method (12) with cellulose extraction thimble (from Whatman Ltd. with 33mm (ID) $\times 94 \mathrm{~mm}$ (length)). After pouring $150 \mathrm{~mL}$ hexane in the extraction flask $(250 \mathrm{~mL})$, the flask was fitted to the extraction apparatus and boiled at such a rate that the hexane refluxed gently for seven hours, the heating was stopped and the thimble was removed from the extraction apparatus. After evaporating hexane for $7 \mathrm{hr}$, the concentrated solution was placed in a desiccator overnight to remove trace amounts of hexane. Moisture content was measured by drying oven method (13). Triplicate samples $(5.0 \mathrm{~g})$ were heated in the oven at $130^{\circ} \mathrm{C}$ for $1 \mathrm{hr}$ and then stored in the desiccator for $30 \mathrm{~min}$.

\section{Detemination of partition coefficient values for each solvent on various cookie models for factorial experi- ment}

Previously determined partition coefficient values (10) of commercial lab-made cookies were: isopropanol $(0.13951 \pm 0.00420)$, methyl ethyl ketone $(0.11429 \pm$ $0.00491)$, toluene $(0.12163 \pm 0.00496)$, ethyl acetate $(0.07427 \pm 0.00351)$, and hexane $(0.04683 \pm 0.00142)$. Kp value of 9 lab-made cookie models with various water and sugar content were determined in a closed system based on the method of Biran et al. (14). Vials $(60 \mathrm{~mL})$ with each cookie $(5.0 \mathrm{~g})$ and blank vials were prepared with sealing of rubber septa and then $0.4 \mu \mathrm{L}$ of each solvent was injected. After storing each bottle for one day more than the determined equilibrium day at $25^{\circ} \mathrm{C}$, a $200 \mu \mathrm{L}$ sample of headspace from each vial was injected into the gas chromatograph (GC) by syringe. These experiments were repeated three times. Partition coefficients of each solvent between each sample and headspace were calculated by the following equation.

$$
\mathrm{Kp}=\frac{\text { Concentration of solvent in food }}{\text { Concentration of solvent in air }}
$$

\section{RESULTS AND DISCUSSION}

Partition coefficient values for each solvent on various cookie models for factorial expeniment

Partition coefficient values for nine lab-made commercial cookie with commercial compositions and nine lab-made cookies with variable sugar and water content measured at $25^{\circ} \mathrm{C}$ are shown in Table 4 and were used to identify the presence and effects of interaction between the two ingredients in the cookies. The presence of any interaction between two ingredients can be judged by diagram and statistical analysis, which are discussed in greater detail below.

\section{Detemination of interaction between sugar and water content by using a diagram method}

The presence of interaction between sugar and water means that a change in sugar produces a different change in the partition coefficient value at other levels of water, and can be judged by diagram study. If the regression lines are not parallel, there is interaction between the two factors (15). On the other hand, if the regression lines are parallel, no interaction is considered to occur. The regression lines were not parallel to each other, so the partitioning behaviors of all five solvents were affected by sugar and water interactions to some extent. For hexane and toluene, the interactions were relatively

Table 4. Kp for printing ink solvents in cookie model systems where $X_{1}$ is sugar ${ }^{1)}, X_{2}$ is water and $X_{3}$ is fat ${ }^{2)}$

\begin{tabular}{cccccccc}
\hline $\mathrm{X}_{1}$ & $\mathrm{X}_{2}$ & $\mathrm{X}_{3}$ & $\begin{array}{c}\text { Ethyl acetate } \\
( \pm \text { STD })\end{array}$ & $\begin{array}{c}\text { Hexane } \\
( \pm \text { STD })\end{array}$ & $\begin{array}{c}\text { Isopropanol } \\
( \pm \text { STD })\end{array}$ & $\begin{array}{c}\text { Methyl ethyl } \\
\text { ketone }( \pm \text { STD })\end{array}$ & $\begin{array}{c}\text { Toluene } \\
( \pm \text { STD })\end{array}$ \\
\hline & Group I & & & & & & \\
10 & 2.5 & 29.5 & $0.0770 \pm 0.0004$ & $0.0496 \pm 0.0003$ & $0.0687 \pm 0.0012$ & $0.0929 \pm 0.0012$ & $0.1418 \pm 0.0010$ \\
10 & 5.4 & 27.8 & $0.0840 \pm 0.0008$ & $0.0494 \pm 0.0003$ & $0.1372 \pm 0.0012$ & $0.1199 \pm 0.0010$ & $0.1381 \pm 0.0002$ \\
10 & 8.3 & 27.1 & $0.0920 \pm 0.0001$ & $0.0501 \pm 0.0001$ & $0.2052 \pm 0.0034$ & $0.1528 \pm 0.0009$ & $0.1361 \pm 0.0003$ \\
& Group II & & & & & & \\
15 & 3.5 & 27.2 & $0.0748 \pm 0.0003$ & $0.0473 \pm 0.0002$ & $0.0878 \pm 0.0024$ & $0.0918 \pm 0.0004$ & $0.1354 \pm 0.0003$ \\
15 & 6.0 & 25.9 & $0.0821 \pm 0.0003$ & $0.0479 \pm 0.0001$ & $0.1440 \pm 0.0044$ & $0.1188 \pm 0.0011$ & $0.1326 \pm 0.0002$ \\
15 & 8.6 & 25.0 & $0.0896 \pm 0.0004$ & $0.0487 \pm 0.0001$ & $0.1957 \pm 0.0035$ & $0.1412 \pm 0.0011$ & $0.1311 \pm 0.0001$ \\
& Group III & & & & & & \\
20 & 2.9 & 26.0 & $0.0734 \pm 0.0005$ & $0.0456 \pm 0.0003$ & $0.0806 \pm 0.0015$ & $0.0836 \pm 0.0012$ & $0.1317 \pm 0.0002$ \\
20 & 5.7 & 24.8 & $0.0802 \pm 0.0005$ & $0.0470 \pm 0.0001$ & $0.1339 \pm 0.0003$ & $0.1075 \pm 0.0011$ & $0.1298 \pm 0.0003$ \\
20 & 8.5 & 23.4 & $0.0860 \pm 0.0007$ & $0.0479 \pm 0.0002$ & $0.1770 \pm 0.0030$ & $0.1282 \pm 0.0013$ & $0.1271 \pm 0.0001$ \\
\hline
\end{tabular}

${ }^{1)} \mathrm{X}_{1}$ is \% in cookie dough, $\mathrm{X}_{2}$ and $\mathrm{X}_{3}$ are final \% in the baked cookie product.

${ }^{2}$ Average of determinations on 3 samples at 1 concentration over $50 \mathrm{ppm} \sim 70 \mathrm{ppm}, \mathrm{N}=27$. 
minor compared to those of the polar solvents. For ethyl acetate and methyl ethyl ketone, under increasing sugar content (from $10 \%$ and $15 \%$ to $20 \%$ ), the regression lines were more anti-parallel and the interactions were relatively stronger at all cases compared to those of other solvents. Qualitatively, it is seen that Kp decreased as sugar increased in all cases. Also, Kp increased as water increased for all cases except toluene. However by just using the factorial diagram method, it was not possible to measure the significance of sugar and water interaction.

Determination of interaction between sugar and water content by using a statistical analysis

Statistical analysis by the F-test method was used to determine the significance of sugar and water interactions and the other single factors on partitioning behavior of each solvent. The partition coefficient values for the factorial experiments on nine lab-made cookies were analyzed statistically by the SAS (JUMP) program using the F-test. The results on the five solvents are shown in Tables 5 9. The F-test indicates whether sugar, water, and sugar-water interaction affected partition coefficient values significantly. In this factorial work, total observations $(\mathrm{N})$ were 27 and total parameters $(\mathrm{P})$ were 5 (intercept, sugar, water, sugar-water interactions and fat). According to the ANOVA table, degree of freedom of each parameter V1 was 1 (P-1) and degree of freedom V2 was 22 (N-P). At the 5.0\% significance lev$\mathrm{el}$, the $\mathrm{F}$ value is 4.30 . Therefore, to affect partition coefficient values significantly, the $\mathrm{F}$ ratio of the parameter should be higher than 4.30 .

The effect of sugar: For each solvent, the F-value of sugar parameter is smaller than the tabulated $\mathrm{F}$ value (4.30) at the 5.0\% significance level. This result showed that sugar did not affect partitioning behavior of the five solvents significantly.

The effect of water: For polar solvents (ethyl acetate, isopropanol and methyl ethyl ketone), the F-value of water is larger than the tabulated $\mathrm{F}$ value at the $5.0 \%$ significance level, and for non-polar solvents (hexane and toluene), the F-value of water is below the significance level. These behaviors indicated that water affected partitioning behavior of the polar solvents significantly, while

Table 5. ANOVA $\left(\right.$ corrected $^{1)}$ ) table of ethyl acetate for factorial work and parameter estimate of each significant factor for determination of regression equation ${ }^{2)}$

\begin{tabular}{lcrrr}
\hline Source & Degree of freedom & Sum of square & F-value & Estimates \\
\hline Slope & 4 & 0.00100218 & & \\
Sugar & 1 & 0.00000111 & 2.9204 & 0.0038567 \\
Water & 1 & 0.00006451 & 169.8422 & -0.000028 \\
Sugar $\times$ Water & 1 & 0.00000186 & 0.8921 & 0.0021464 \\
Fat & 1 & 0.00000456 & 12.0046 & 0.001012 \\
\hline Intercept & & & & \\
\hline Error & 22 & 0.0000836 & & \\
\hline Total $\left(\mathrm{C}^{1)}\right)$ & 26 & 0.00101054 & & \\
\hline
\end{tabular}

${ }^{1)}$ Corrected means deletion of intercept from the ANOVA table.

${ }^{2)} \mathrm{Kp}=0.001012+0.0038567 \mathrm{X}_{2}+0.0021464 \mathrm{X}_{3}-0.000028 \mathrm{X}_{1} \mathrm{X}_{2}\left(\mathrm{R}^{2}=0.99\right) . \mathrm{X}_{1}$ is \% of sugar in cookie dough, $\mathrm{X}_{2}$ and $\mathrm{X}_{3}$ are final \% of water and fat in baked cookie.

Table 6. ANOVA (corrected ${ }^{1)}$ ) table of hexane for factorial work and parameter estimate of each significant factor for determination of regression equation ${ }^{2)}$

\begin{tabular}{lcccc}
\hline Source & Degree of freedom & Sum of square & F-value & Estimates \\
\hline Slope & 4 & 0.00005002 & & \\
\hline Sugar & 1 & 0.00000021 & 3.2907 & \\
Water & 1 & 0.00000011 & 51.7479 & 0.0000376 \\
Sugar $\times$ Water & 1 & 0.00000327 & 0.0010838 \\
Fat & 1 & 0.00000116 & 0.0177938 \\
\hline Intercept & & & & 0.001012 \\
\hline Error & 22 & 0.0000139 & \\
\hline Total $\left(\mathrm{C}^{1)}\right)$ & 26 & 0.00005140 & & \\
\hline
\end{tabular}

${ }^{1)}$ Corrected means deletion of intercept from the ANOVA table.

${ }^{2)} \mathrm{Kp}=0.0177938+0.0010838 \mathrm{X}_{3}+0.0000376 \mathrm{X}_{1} \mathrm{X}_{2}\left(\mathrm{R}^{2}=0.96\right) . \mathrm{X}_{1}$ is \% of sugar in cookie dough, $\mathrm{X}_{2}$ and $\mathrm{X}_{3}$ are final \% of water and fat in baked cookie. 
Table 7. ANOVA $\left(\right.$ corrected $^{1)}$ ) table of isopropanol for factorial work and parameter estimate of each significant factor for determination of regression equation ${ }^{2)}$

\begin{tabular}{lcccc}
\hline Source & Degree of freedom & Sum of square & F-value & Estimates \\
\hline Slope & 4 & 0.05999161 & & \\
\hline Sugar & 1 & 0.00002847 & 2.2922 & 0.0290727 \\
Water & 1 & 0.00366567 & 295.105 & -0.000646 \\
Sugar $\times$ Water & 1 & 0.0009681 & 77.9368 & 0.2504 \\
Fat & 1 & 0.00000311 & & 0.0475888 \\
\hline Intercept & & & & \\
\hline Error & 22 & 0.00027327 & & \\
\hline Total $\left(C^{1)}\right)$ & 26 & 0.06026488 & & \\
\hline
\end{tabular}

${ }^{1)}$ Corrected means deletion of intercept from the ANOVA table.

${ }^{2)} \mathrm{Kp}=0.0475888+0.0290727 \mathrm{X}_{2}-0.000646 \mathrm{X}_{1} \mathrm{X}_{2}\left(\mathrm{R}^{2}=0.99\right) . \mathrm{X}_{1}$ is \% of sugar in cookie dough, $\mathrm{X}_{2}$ is final \% of water and fat in baked cookie.

Table 8. ANOVA (corrected $^{1)}$ ) table of methyl ethyl ketone for factorial work and parameter estimate of each significant factor for determination of regression equation ${ }^{2)}$

\begin{tabular}{lcccc}
\hline Source & Degree of freedom & Sum of square & F-value & Estimates \\
\hline Slope & 4 & 0.01317199 & & \\
Sugar & 1 & 0.00000194 & 0.9720 & 0.0137894 \\
Water & 1 & 0.00082466 & 414.0183 & -0.000222 \\
Sugar $\times$ Water & 1 & 0.00011471 & 57.5896 & 0.0031639 \\
Fat & 1 & 0.00000991 & 4.9740 & -0.033988 \\
\hline Intercept & & & & \\
\hline Error & 22 & 0.0004382 & & \\
\hline Total $\left(\mathrm{C}^{1)}\right)$ & 26 & 0.01321581 & & \\
\hline
\end{tabular}

${ }^{1)}$ Corrected means deletion of intercept from the ANOVA table.

${ }^{2)} \mathrm{Kp}=-0.033988+0.0137894 \mathrm{X}_{2}+0.0031639 \mathrm{X}_{3}-0.000222 \mathrm{X}_{1} \mathrm{X}_{2}\left(\mathrm{R}^{2}=0.98\right) . \mathrm{X}_{1}$ is \% of sugar in cookie dough, $\mathrm{X}_{2}$ and $\mathrm{X}_{3}$ are final \% of water and fat in baked cookie.

Table 9. ANOVA (corrected ${ }^{1)}$ ) table of toluene for factorial work and parameter estimate of each significant factor for determination of regression equation ${ }^{2)}$

\begin{tabular}{lcccc}
\hline Source & Degree of freedom & Sum of square & F-value & Estimates \\
\hline Slope & 4 & 0.00048889 & & \\
Sugar & 1 & 0.00000065 & 3.1487 & 0.0000288 \\
Water & 1 & 0.00000034 & 1.6618 & 0.0023827 \\
Sugar $\times$ Water & 1 & 0.00000192 & 0.3488 & 0.0741477 \\
Fat & 1 & 0.00000562 & 27.3265 & \\
\hline Intercept & & & & \\
\hline Error & 22 & 0.0000452 & & \\
\hline Total $\left(\mathrm{C}^{1)}\right)$ & 26 & 0.00049341 & & \\
\hline
\end{tabular}

${ }^{1)}$ Corrected means deletion of intercept from the ANOVA table.

${ }^{2)} \mathrm{Kp}=0.0741477+0.0023827 \mathrm{X}_{3}+0.0000288 \mathrm{X}_{1} \mathrm{X}_{2}\left(\mathrm{R}^{2}=0.89\right) . \mathrm{X}_{1}$ is \% of sugar in cookie dough, $\mathrm{X}_{2}$ and $\mathrm{X}_{3}$ are final \% of water and fat in baked cookie.

it did not affect the non-polar solvents. These results were in accord with hydrogen bonding attraction between the polar solvents and water.

The effect of sugar and water interaction: For all of the solvents, the F-value of sugar and water interaction is larger than the tabulated $\mathrm{F}$ value at the $5.0 \%$ level, which means sugar-water interaction affected partitioning behavior significantly. This result indicated that there could be a crystallinity effect that depends on a competition for the water. For example, the sugar can crystallize and cover active sites or produce interaction between the flour and fat. This would change the ability of the sol- 
Table 10. Calculated $\mathrm{Kp}$ by using a regression equation with $\% \mathrm{H}_{2} \mathrm{O}$, \% fat and \% sugar, and experimental Kp values for lab-made cookies for each solvent

\begin{tabular}{|c|c|c|c|}
\hline Solvent & Calculated $\mathrm{Kp}^{1)}$ & Experimental Kp & Difference $^{2)}$ \\
\hline Ethyl acetate & 0.07287 & 0.07427 & $1.92 \%$ \\
\hline Hexane & 0.04779 & 0.04683 & $2.01 \%$ \\
\hline Isopropanol & 0.15182 & 0.13951 & $8.11 \%$ \\
\hline Methyl ethyl ketone & 0.10094 & 0.11429 & $13.23 \%$ \\
\hline Toluene & 0.13568 & 0.12163 & $10.36 \%$ \\
\hline
\end{tabular}

${ }^{1)} \mathrm{Kp}$ values by using regression equation from the factorial experiment.

${ }^{2)} \%$ difference between the calculated $\mathrm{Kp}$ by regression equation and the experimental $\mathrm{Kp}$ of \#2 lab-made cookie.

vents to penetrate and interact.

The effect of fat: For toluene, hexane, ethyl acetate and methyl ethyl ketone, the F-value of fat is larger than the tabulated $\mathrm{F}$ value at the $5.0 \%$ level, and for isopropanol, the value is smaller. This behavior means fat affected partitioning behavior significantly in all of solvents except isopropanol. Among them, toluene was affected most significantly.

Prediction of partitioning behavior of cookie with regression equation using $\% \mathrm{H}_{2} \mathrm{O}, \%$ fat and $\%$ sugar

Statistical analysis by the SAS computer program determined a parameter estimation of each significant factor in each solvent and yielded a regression equation and are shown in Tables $5 \sim 9$. Kp can be calculated by inserting \% water and \% fat found by analysis in the cookie, and \% sugar in the cookie formula. For example, the hexane regression equation was as follows:

$$
\begin{aligned}
\mathrm{Kp}= & 0.0177938+0.0010838 \times 24.83 \text { (fat content) } \\
& +0.0000376 \times 15.18 \text { (sugar content) } \\
& \times 5.41 \text { (water content) }=0.04779
\end{aligned}
$$

The calculated Kp values using this regression equation and experimental $\mathrm{Kp}$ of representative lab-made cookies for each solvent were shown in Table 10. The $\%$ difference between the calculated $\mathrm{Kp}$ and the experimental $\mathrm{Kp}$ of lab-made cookies in five solvents ranged from $1.92 \%$ to $13.23 \%$. Previous research (11) showed the \% difference between the Kp calculated by using baked cookie ingredient composition and experimental $\mathrm{Kp}$ of lab-made cookie in five solvents ranged from 11.25 to 18.20 . Therefore, the calculated $\mathrm{Kp}$ values determined with the correction factor were more reflective of the interaction between sugar and water than the Kp values of each ingredient after baking.

\section{ACKNOWLEDGMENT}

I would like to express my sincere appreciation to Dr. George Halek in Rutgers, the State University of New Jersey, for his kind guidance, strong support, and encouragement in this study and this experiment training.

\section{REFERENCES}

1. Kumai M, Koizumi A, Saito K. 1983. A nationwide survey on organic solvent compounds in various solvent product. Ind Health 21: 185-197.

2. Gilbert SG. 1976. Migration of minor constituents from food packaging materials. J Food Sci 41: 955-958.

3. Vivek G, John DF. 1997. Migration and sorption phenomena in packaged foods. Crit Rev Food Sci Nutr 37: 519-559.

4. Halek GW, Efstratios H. 1988. Partition coefficients of food package ink solvents in soybean oil, chocolate liquor, and a high fat baked product. J Food Sci 53: 568-570, 596.

5. Halek GW, Levinson JJ. 1989. Partitioning and absolute flavor threshold interaction of aliphatic and aromatic food packaging solvents in high fat cookies. J Food Sci 54: 173-176.

6. Letinski J, Halek GW. 1992. Interaction of citrus flavor compounds with polypropylene films of varying crystallinities. J Food Sci 57: 481-484.

7. Halek GW, Chan A. 1994. Partitioning and absolute flavor threshold interactions of aliphatic food packaging solvents homologs in high-fat cookies. J Food Sci 59: 420-423.

8. Charara ZN, Williams JW, Schmidtt RH, Marshall MR. 1992. Orange flavor absorption into various polymeric packaging materials. J Food Sci 57: 963-966, 972.

9. Konczal JB, Harte BR, Hoojjat P, Giacin JR. 1992. Apple juice flavor compounds sorption by sealant films. J Food Sci 57: 967-972.

10. An DJ. 2004. Compositional and structural effects on migration behavior of printing ink solvents on lab-made cookies. Food Sci Biotechnol 13: 707-711

11. An DJ. 2009. Determination and prediction of partition coefficient value $(\mathrm{Kp})$ for printing ink solvents on cookie from $\mathrm{Kp}$ of each cookie ingredient. J Food Sci 14: 246-251.

12. Paquot C, Hautfenne A. 1987. Preparation of the fatty acid methyl esters. In Standard Methods for the Analysis of Oils Fats and Derivatives. 7th ed. Blackwell Scientific Publications, Cambridge, MA, USA. p 123.

13. AOAC. 1980. Method 14.004. Official methods of analysis. 14th ed. Association of Official Analytical Chemists, Washington, DC, USA. p 211.

14. Biran D, Giacin JR, Hayakawa K, Gilbert SG. 1979. Sorption of vinylchloride by selected food constituents. J Food Sci 44: 59-61.

15. Coleman DE, Montgomery DC. 1993. A systematic approach to planning for a designed industrial experiment. Technometrics 35: 1-28.

(Received October 23, 2009; Accepted November 25, 2009) 